\title{
Comunicación y desinformación en tiempos de COVID-19 en Ecuador
}

\author{
Communication and Misinformation
}

in Times of COVID-19 in Ecuador

Recepción: 28/01/2021, revisión: 04/03/2021,

aceptación; 29/03/2021, publicación: septiembre de 2021

https://revistas.uasb.edu.ec/index.php/uru

(ID) Krushenka Bayas Ramírez

info@krushenka.com

Shifta, centro adscrito a la Universidad Pompeu Fabra de Barcelona (Quito, Ecuador)

https://orcid.org/0000-0002-9346-2049

DOI https://doi.org/10.32719/26312514.2021.4.5

\section{Resumen}

La pandemia del COVID-19 desnudó no solo los problemas estructurales de los sistemas de salud a escala global, sino también problemas en la comunicación eficaz de la crisis y cómo evitarla o al menos contenerla. Estos problemas se vieron afectados asimismo por la proliferación de desinformación sobre temas tan variados como tratamientos, síntomas, orígenes y formas de prevenir su contagio. Si bien las plataformas de verificación cumplen con una labor importante para contrarrestar a las denominadas fake news, la cantidad de información y desinformación que circuló en los primeros meses de la pandemia fue tan grande que se necesita un esfuerzo que abarque más frentes para poder comunicar con eficiencia el fenómeno y sus diferentes aristas. Las verificaciones hechas por Ecuador Chequea durante el primer semestre de 2020 fueron clasificadas bajo criterios cualitativos, como las emociones que provocan o el tema al que se refieren, y mediante el uso de herramientas de diseño de la información y visualización de datos se desarrollaron piezas gráficas que muestran la relación entre la producción de información y el desarrollo de la pandemia en Ecuador. Hecho esto, era necesario comunicar los hallazgos y este trabajo presenta el desarrollo y los resultados cuantitativos de la campaña de comunicación en redes sociales, ideada para contribuir a educar al público en general al momento de distinguir la desinformación.

\section{Abstract}

The COVID-19 pandemic exposed not only the structural problems of health systems on a global scale, but also problems in effective communication of the crisis and how to avoid or at least contain it. These problems were also affected by the proliferation of misinformation on topics as varied as treatments, symptoms, origins or ways to prevent its spread. Although, the verification platforms fulfill an important task to counteract the so-called fake news, the amount of information and misinformation that circulated in the first months of the pandemic was so great that an effort is needed 
that covers more fronts to be able to communicate efficiently the phenomenon and its different edges. The verifications made by Ecuador Chequea during the first semester of 2020 were classified under qualitative criteria such as the emotions they provoke or the subject to which they refer and through the use of Information Design and Data Visualization tools, graphic pieces were developed that show the relationship between the production of information and the development of the pandemic in Ecuador. Once this was done, it was necessary to communicate the findings and this work presents the development and quantitative results of the communication campaign on social networks designed to help educate the general public to distinguish misinformation.

Palabras clave · Keywords

Desinformación, COVID-19, infodemia, visualización de datos, comunicación, fake news.

Disinformation, COVID-19, infodemic, data visualization, communication, fake news.

Los rumores, la desinformación y las fake news no son nuevos, pero la pandemia del COVID-19 y la situación atípica vivida en los últimos meses de encierro e incertidumbre hicieron que la cantidad de información que se difunde por medios de comunicación, redes sociales y otras vías fuera tan grande que muchas veces se vuelva muy difícil distinguir entre información verdadera y falsa. La Organización Mundial de la Salud (OMS 2020) ha denominado a este fenómeno infodemia masiva; el mismo Tedros Adhanom, su director general, declaró en la Conferencia de Seguridad de Múnich, el 14 de febrero de 2020, que actualmente estamos luchando contra una epidemia y una infodemia, y que la segunda puede ser igual de peligrosa.

La desinformación suele tener objetivos claros, entre ellos lograr réditos económicos, conseguir relevancia como hacker al romper una barrera de seguridad para diversos fines, afectar la credibilidad de una persona u organización, polarizar el debate sobre temas específicos y atentar contra la seguridad nacional (GB Government Communication Service 2019). La lucha contra la desinformación empieza por la educación y por proveer a la población de fuentes confiables, y la estrategia de la OMS ha sido acercarse a las redes sociales y a Google para desarrollar políticas conjuntas que eviten la difusión de noticias falsas y contribuyan a que la población pueda acceder a información adecuada, oportuna y veraz (Zarocostas 2020).

La respuesta a la desinformación puede tener varios enfoques. Uno de ellos es la identificación y para esto es fundamental "monitorear la información que se difunde tan rápidamente, verificar si es correcta, identificar quién la publicó, y por qué" (Posetti y Bontcheva 2020a, 5). En este contexto, la Unesco acuñó el término desinfodemia para referirse a la gran cantidad de información falsa sobre el COVID-19 "por la enorme 'carga 
viral' de desinformación potencialmente mortífera", considerada una epidemia paralela (Posetti y Bontcheva 2020b, 2).

En este contexto, las plataformas de verificación juegan un rol fundamental en la lucha contra la difusión de noticias falsas. En el país, Ecuador Chequea funciona desde octubre de 2016 como una "experiencia colaborativa entre la sociedad civil, la academia y el periodismo" (Ecuador Chequea 2021), que, además de analizar la información engañosa que circula en redes sociales, también verifica el discurso oficial de autoridades y actores de coyuntura.

Es importante comprender que la comunicación ha sufrido cambios apresurados debido al acceso a internet y la velocidad con que se produce información, ya sea por medio de textos, fotografías o videos. Es así que

en este nuevo paradigma, los usuarios de la comunicación — que ya no es vertical ni unidireccional- adquieren un papel protagónico como emisores. La generalización de las TIC ha permitido el acceso a internet por intermedio de computadores y dispositivos móviles, pasando por el rápido aprendizaje de uso por parte de los usuarios, incluso de personas con experticia nula en navegación de internet. (Cusot y Palacios 2019)

En este terreno es fácil que los rumores se esparzan con rapidez. La desinformación en Ecuador aprovecha la crisis sanitaria del COVID-19 y, mediante una serie de campañas simultáneas y articuladas, busca desprestigiar al Gobierno (Código Vidrio 2020). Por esta razón, solo en el primer semestre de 2020, Ecuador Chequea verificó y desmintió 246 noticias falsas que circularon en redes sociales como WhatsApp, Facebook y Twitter.

Pero para que la lucha sea efectiva no basta con ese esfuerzo. El siguiente paso debe ser comunicar efectivamente no solo las verificaciones, sino también identificar las similitudes o diferencias entre ellas, con el objetivo de darles un contexto que sirva para que el público pueda identificarlas.

Toda imagen colocada en el espacio público comunica indefinidamente un espectro impredecible de mensajes. Además de transmitir el mensaje específico que la ha generado, también contribuye a la construcción de la cultura en el más amplio sentido de la palabra, promoviendo modelos de pensamiento y conducta que influyen en la manera en que la gente se relaciona con otros mensajes, con las otras cosas y con la otra gente. (Frascara 1999)

El diseño de la información (DI) no es una disciplina nueva, pero en 2020 cobró una gran importancia, ya que los mapas, esquemas, infografías y gráficos de diversa naturaleza han ayudado a entender la extensión y gravedad de la pandemia, así como sus síntomas, formas de prevenir el contagio y tratamientos. Gracias a la visualización de datos (VD) se puede convertir una tabla llena de números en un mapa interactivo que haga a esas cifras, mediante colores y formas, digeribles y atractivas para el público.

La VD "implica la creación y el estudio de la representación visual de datos" (Shaoqiang 2017). Los seres humanos son seres visuales y adquieren más información mediante 
la visión que a través de todos los otros sentidos juntos. Por esta razón, las visualizaciones son cada vez más importantes en los procesos cognitivos (Ware 2013).

Hacer visibles fenómenos de la realidad es mucho más complejo que volverlos evidentes. Por eso, Costa (1998) sostiene que visualizar es un proceso y un resultado que se cristaliza en un acto de transferencia de conocimientos, entre el visualista y el receptor humano, mediante el documento elaborado. Entonces, visualizar pone en común y en conocimiento un hecho de comunicación por medios gráficos.

De esta forma, la VD se debe considerar como una herramienta de comunicación que puede servir para transformar un mensaje frío o complejo en uno más simple. Una visualización puede contener gran cantidad de información, pero al presentarla de manera organizada, jerarquizada y adecuada a un público específico, dicha información se vuelve digerible.

\section{Metodología y materiales}

La primera fase de esta investigación surge como respuesta a la necesidad de comunicar de una manera más sencilla, pero a la vez global, los insights que se desprenden del estudio de las 246 verificaciones que realizó Ecuador Chequea en el país entre enero y junio de 2020. Además, relaciona esta información con los datos de la pandemia generados por instituciones del Estado como el Registro Civil y el Ministerio de Salud Pública. El artículo "Visualización del contexto de las fake news para entender la infodemia" (Bayas 2020) recoge este análisis y, utilizando herramientas de DI y VD, ofrece una serie de gráficos o visualizaciones que ayudan a comprender cómo evolucionó el fenómeno de la desinformación en los primeros seis meses de 2020, los más álgidos de la pandemia en el país.

Dada la importancia que tiene la comunicación en estos tiempos, esta segunda fase presenta la campaña en redes sociales, cuyo objetivo principal es conseguir una mayor difusión de esos hallazgos y contribuir a la educación del público para detectar la desinformación al identificar y mostrar características comunes o únicas.

Para el desarrollo de esta campaña se partió de la pregunta “¿Cómo reconozco una fake news?". Los conceptos principales son conocer las relaciones entre la producción de desinformación y la realidad, y cortar la cadena de desinformación (esta etiqueta o hashtag -\#CortaLaCadena- acompaña todas las publicaciones).

Para construir las piezas comunicaciones se tomaron porciones de las visualizaciones generadas en la primera fase de la investigación. Así, se desarrollaron piezas gráficas para redes que mostraran características comunes de las fake news, detalles desconocidos de su origen y el objetivo de su difusión.

Según la última encuesta de Tecnologías de la Información y Comunicación realizada por el Instituto Nacional de Estadística y Censos (INEC) en diciembre de 2019, 
en Ecuador el 56,1 \% de hogares del área urbana y el 21,6 \% del área rural tiene acceso a internet, pero aún se considera un $11,4 \%$ de analfabetismo digital a escala nacional, que llega hasta un $20 \%$ en el área rural. En cuanto a las redes sociales, la más usada es Facebook, con un 78,8 \% de la población entre 15 y 24 años y, aunque con el paso de los años su uso disminuye, se considera que la utiliza el $55,4 \%$ de la población, lo que la convierte en la de mayor penetración en el país, seguida de WhatsApp (52\%). El 73,8 \% de los individuos entre 25 y 34 años usa esta red de mensajería, que es la más utilizada por la gente entre 45 y 64 años, con un 48,4\%. Instagram es la tercera, con un $18,2 \%$ a nivel nacional y un $32 \%$ de preferencia en jóvenes entre 15 y 24 años. Twitter es usada por un $8,8 \%$ de ecuatorianos, con un pico de $14,9 \%$ de usuarios en la población entre 25 y 34 años.

Con base en estos datos, las redes elegidas para la campaña fueron Facebook, Instagram y Twitter; esta última, a pesar de su penetración inferior, es muy utilizada para obtener información y difundir desinformación. Para este efecto, se crearon perfiles en esas tres redes bajo el nombre ActualData, con la idea de replicar contenidos similares y visualizaciones interesantes y coyunturales, pero sobre todo para ayudar a difundir la campaña.

Figura 1

Identificador del perfil ActualData en redes sociales

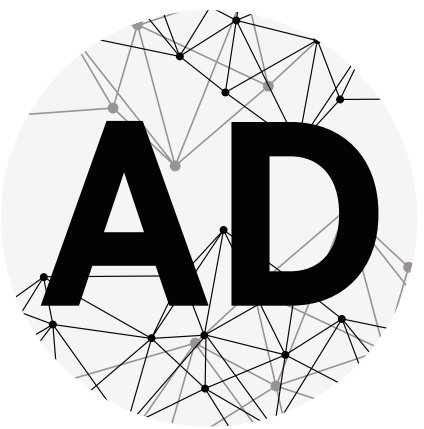

Fuente y elaboración propias

\section{Fases}

La campaña, para la cual se usó el hashtag \#CortaLaCadena, fue concebida en tres fases. En la primera, de expectativa, se mostraron frases y datos de algunos hallazgos de la investigación, y se invitó a la audiencia a estar pendiente de la siguiente fase. Esta etapa inicial tuvo lugar del 1 al 13 de noviembre de 2020, en los días previos al lanzamiento del volumen 4 de \#PerDebate, en la que se publicó un artículo con los hallazgos de la investigación. 
La revista se publicó a propósito del X Congreso \#PerDebate organizado por la Universidad San Francisco de Quito.

Para esta fase se emitieron cinco piezas alternando los días y las redes, y con ello se consiguió que los perfiles ganaran unos pocos seguidores. Cada una de las piezas estaba acompañada de un texto que aportaba más datos tomados de la investigación inicial. En esta fase no se invirtió ningún presupuesto y todo el engagement fue orgánico.

Algunos de los mensajes usados en esta fase fueron:

- 246 fake news circularon en Ecuador en los primeros 6 meses de 2020.

- El 23 de marzo se verificaron 15 noticias falsas. ¿Sabes qué pasaba en el país en ese momento?

- Suplantar: Sustituir una cosa por otra, especialmente de forma fraudulenta. La suplantación es el camino más común de las fake news.

- Las fake news buscan hacerte sentir miedo o ira, así es más fácil que las sigas difundiendo.

- La mayoría de fake news salen de fuentes anónimas para afectar al gobierno.

Figura 2

Arte de la campaña de expectativa

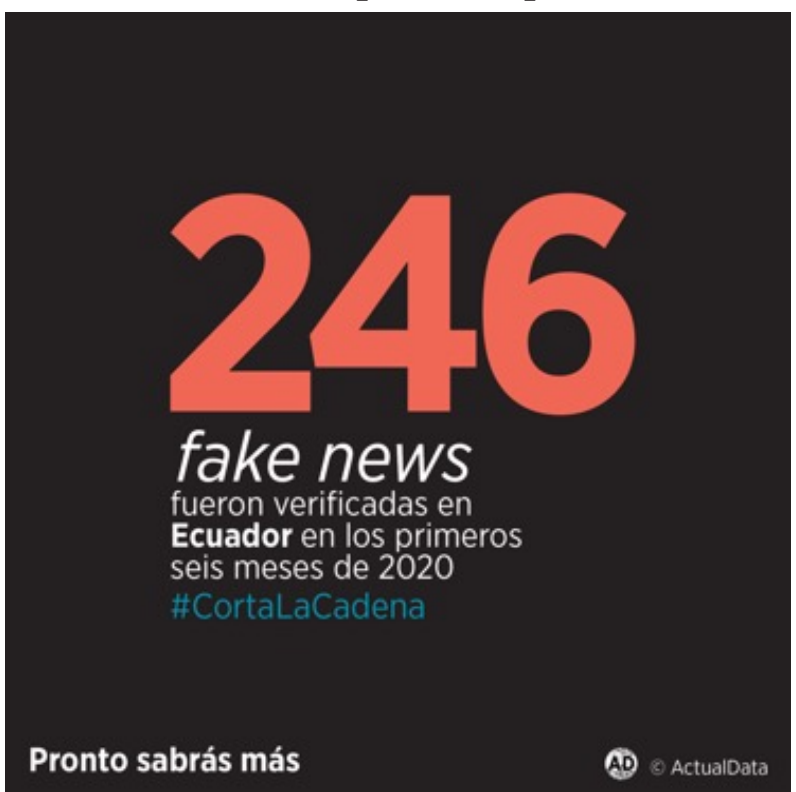

Fuente y elaboración propias 
Figura 3

\section{Publicación de la campaña de expectativa}

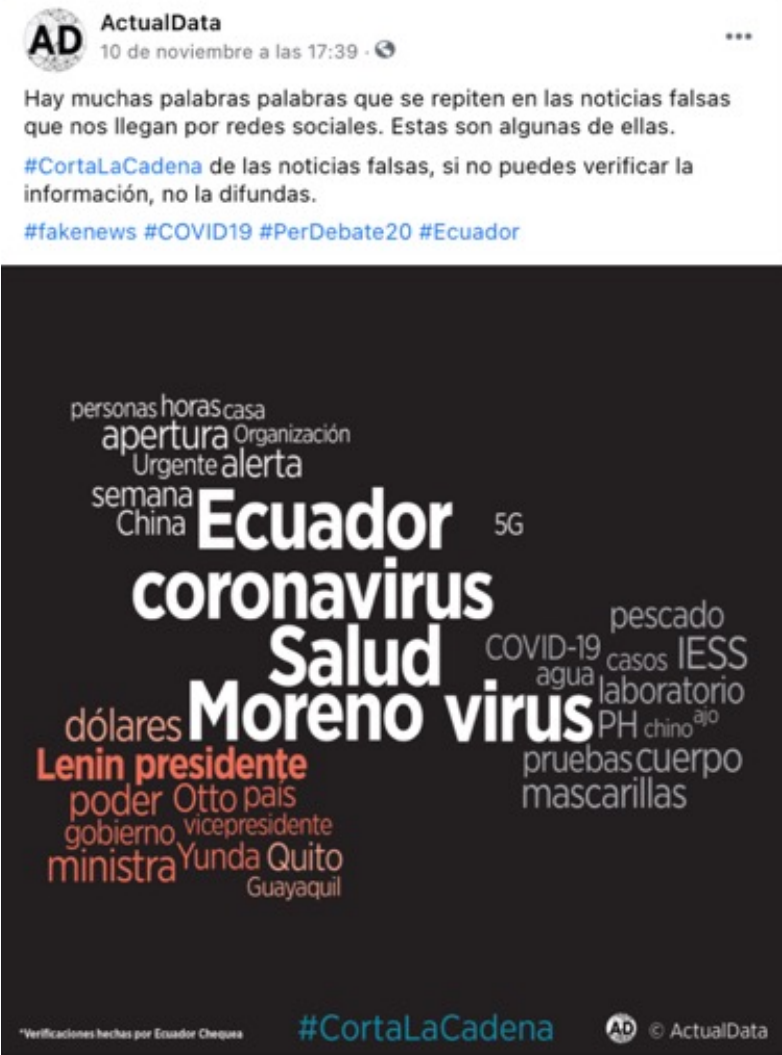

Fuente: Perfil de Facebook de ActualData

La segunda fase de lanzamiento, que tuvo lugar a partir del 15 de noviembre con datos más concretos, invitaba a leer el artículo ya publicado. Esta fase también incluía cinco artes básicos que podrían ser modificados en las siguientes semanas para adaptarse a las necesidades de la campaña; fueron publicados en los perfiles de las tres redes sociales mencionadas anteriormente. En un principio no se invirtió ningún presupuesto y su exposición fue orgánica hasta determinar qué red generaba más engagement. Al ser Facebook la de mayor penetración en Ecuador, esa tuvo más interacciones y hacia ella se enfocaron más recursos. Se invirtió un presupuesto de USD 10 para cada publicación de esta fase, distribuido en un período de cinco días.

Cada pieza iba acompañada de un texto que aportaba algo más información sobre el tema. Además, se incluía el enlace para leer el artículo, se mencionaban perfiles invo- 
lucrados en la investigación -Ecuador Chequea y \#PerDebate-, y se hacía uso de varias etiquetas: \#Infodemia, \#Pandemia, \#COVID19, \#Ecuador y, por supuesto, el principal de la campaña, \#CortaLaCadena.

Los mensajes de esta fase giran en torno a las características de la desinformación:

- Una radiografía de la desinformación

- Las emociones y la desinformación

- El flujo de la desinformación

- El ritmo de la desinformación

- Los temas de la desinformación

Finalmente, la campaña tuvo una tercera fase, o fase de mantenimiento, prevista para los siguientes dos meses: diciembre de 2020 y enero de 2021. Así, la extensión total de la exposición fue de tres meses.

Figura 4

Arte de la fase de lanzamiento

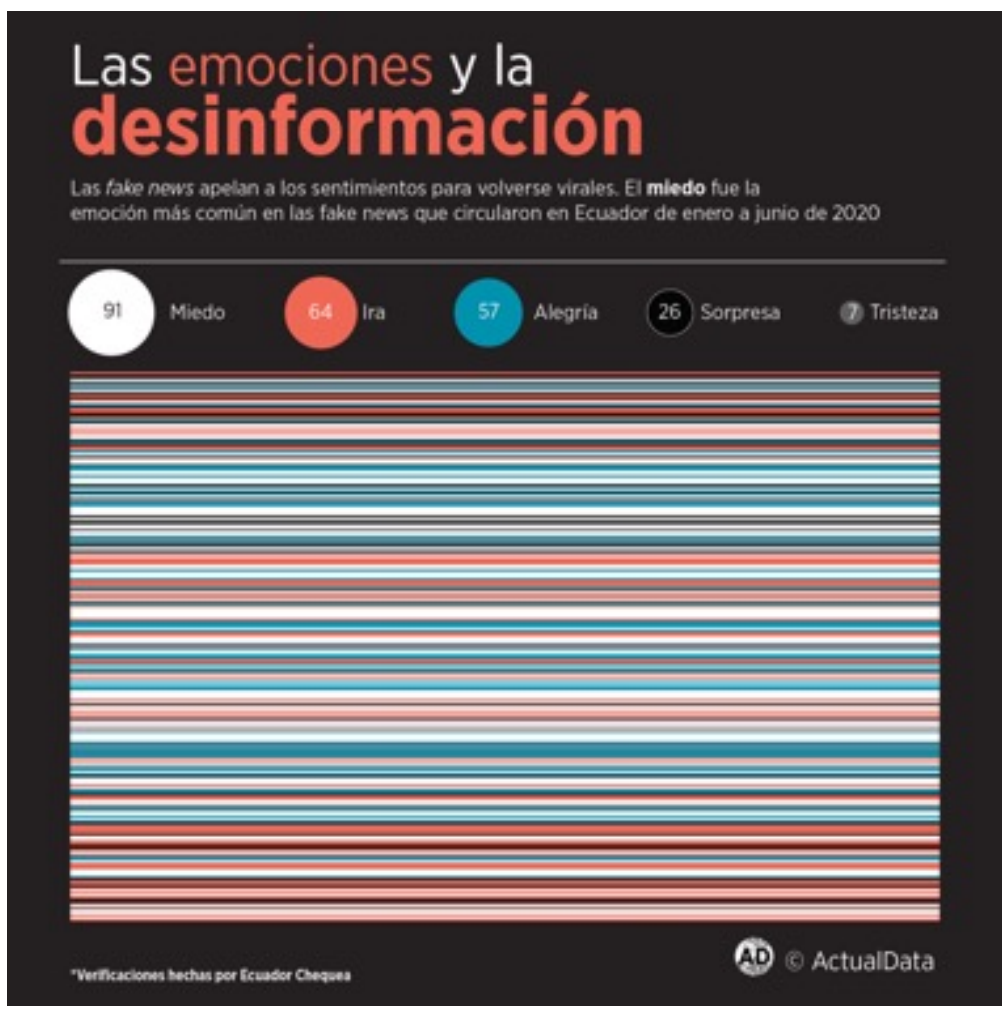

Fuente y elaboración propias 


\title{
Figura 5
}

\section{Publicación de la fase de lanzamiento}

\begin{abstract}
AD ActualData
La desinformación abarca principalmente temas sobre la pandemia como tratamientos milagrosos o número de casos a nivel mundial, $\mathrm{y}$ temas de política referentes a medidas tomadas por el Gobierno y personajes. \#CortaLaCadena de las noticias falsas. \#ShareKnowledge \#COVID19 \#Ecuador Translate Tweet
\end{abstract}

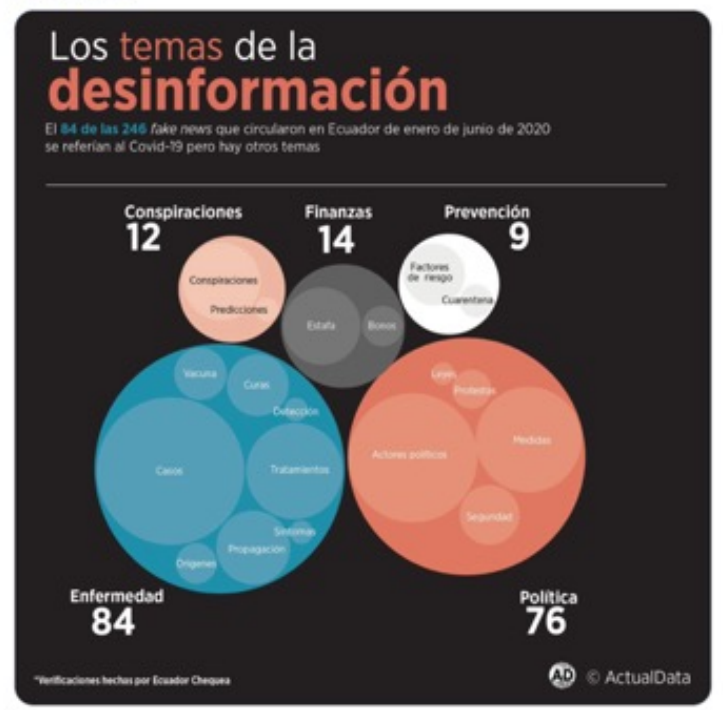

6:27 PM - Nov 28, 2020 - Twitter Web App

Fuente: Perfil de Twitter de ActualData

La estrategia para esta etapa fue seguir los debates que se suscitaran en redes sobre la desinformación y el COVID-19, para insertar los artes ya elaborados u otros nuevos que se generaran a partir de las interacciones. Además, para volver más atractivos los perfiles creados en redes sociales, se incluyó en ellos información proveniente de otras fuentes pero que girara en torno a las mismas temáticas: COVID-19, desinformación, visualización de datos, etc. Esta tercera etapa también necesitaba de un presupuesto que ayudara a promover las publicaciones, pero se evitó utilizarlo durante las fiestas de diciembre, cuando se sabe que hay demasiados mensajes circulando y los recursos serían desperdiciados. 


\section{Públicos}

Hubo dos públicos a los que se aspiraba llegar con esta información. El primero era un público especializado que incluía a hombres y mujeres de 20 a 55 años, periodistas, estudiantes de Comunicación y gente interesada en el tema de las fake news, la desinformación y la pandemia, que habitaran principalmente en Ecuador, con educación superior y un nivel socioeconómico medio y medio alto. A este grupo le interesa mantenerse informado de la actualidad mundial y local: consumen noticias directamente de los medios de comunicación, pero también de redes sociales, pues poseen perfiles al menos en una de las utilizadas para esta campaña. Es gente que gusta de la lectura, reflexiva y con opiniones claras sobre los temas coyunturales de la sociedad, como el feminismo, la inclusión y el medio ambiente. Este público está pendiente de los eventos del congreso \#PerDebate y a él se apuntó sobre todo durante la primera fase de la campaña.

El público secundario incluía a hombres y mujeres de 18 a 65 años que habitaran en Ecuador, con diversas ocupaciones y expuestos constantemente a la desinformación. Este grupo tiene acceso a internet y usa redes sociales con regularidad. Tiene un nivel socioeconómico medio bajo, medio y medio alto, y un nivel de estudios por lo menos secundario. Es un grupo diverso con múltiples intereses, pero sus miembros comparten el gusto por conocer la actualidad mundial y nacional y mantenerse informados por diferentes fuentes; cuentan con al menos un perfil en alguna de las redes que incluye la campaña. En ocasiones, la ingenuidad o el desconocimiento de los mecanismos usados para difundir información falsa les dificulta o les impide diferenciar una noticia falsa de una real.

\section{Estrategia}

Para conseguir la difusión de esta investigación, el primer canal fue el artículo publicado en 2020 en el volumen 4 de la revista académica \#PerDebate, con el que se apuntó a un público especializado, aunque reducido. Para llegar a un público general se desarrolló la campaña en las redes sociales Facebook, Instagram y Twitter, enganchada a las etiquetas que generó el congreso en la primera fase. Para las fases posteriores se mencionaron las redes, medios, personajes o instituciones involucradas en el tema de desinformación, periodismo y la pandemia.

\section{Análisis y resultados}

Luego de tres meses al aire, la campaña ha servido para difundir las visualizaciones y la investigación publicada en el artículo académico. Las visitas, descargas y citas son la manera de medir la difusión del artículo. La campaña en redes se puede medir con interacciones, visitas, clics y alcance en general.

La campaña inició con perfiles sin seguidores en tres redes sociales y, aunque al 28 de enero de 2020 suman menos de 200, solo en Facebook se ha conseguido alcanzar a más de 
42000 personas, con 203 visitas a la publicación del artículo en la revista \#PerDebate. Así, se logró que este fuera descargado 96 veces: 44 en noviembre de 2020, 25 en diciembre y otras 27 en enero de 2021; aún no se registran citaciones. Todo esto se consiguió con una inversión de USD 40. La campaña terminó en el mes de enero de 2021 tras una pausa durante las fiestas, debido a que la cantidad de publicidad que circula en redes en esa época podía opacar la atención buscada con estas piezas.

La publicación que consiguió más interacciones fue la titulada "El flujo de la información”, que muestra, mediante un diagrama de Sankey, que la fuente más común de la información falsa suele ser anónima y que el Gobierno es el más afectado por su difusión. Únicamente esta publicación sumó 96 comentarios, entre originales y respuestas; además, fue compartida 24 veces y consiguió 244 reacciones, de las cuales 243 fueron positivas. En suma, se logró un alcance de más de 12000 personas. Se debe mencionar aquí que el alcance en campañas digitales es estimado, dado que es imposible determinar si más de una persona vio la publicación cada vez que se la visitó.

\section{Gráfico 1}

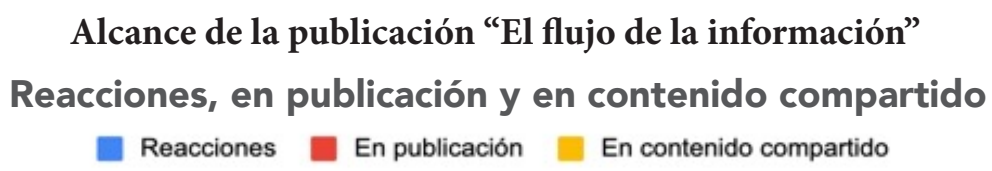

200

150

152152
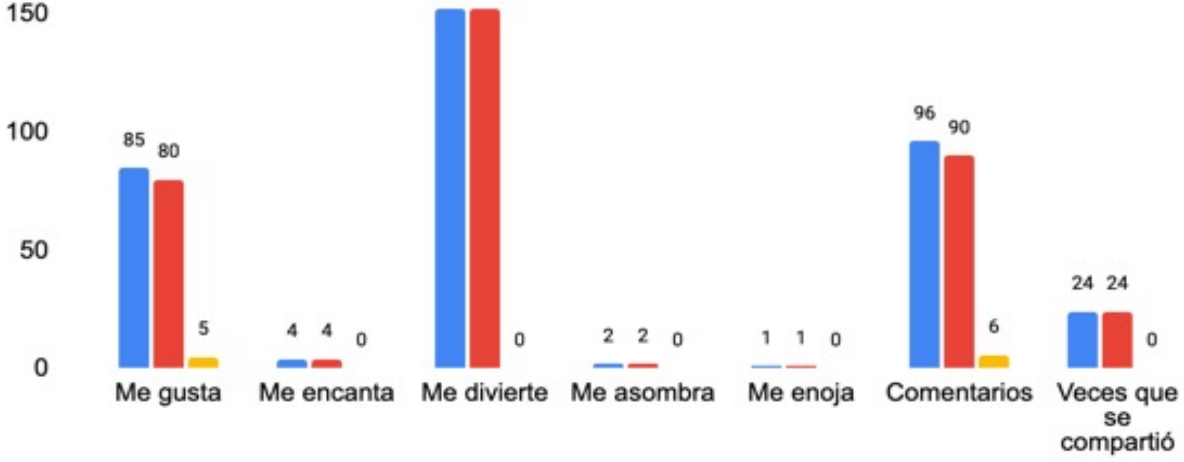

Fuente: Perfil de Facebook de ActualData

Por otra parte, la publicación "Las emociones y la desinformación" tuvo un alcance aproximado de 12113 personas, aunque solo tuvo solo dos comentarios, apenas 18 interacciones y se compartió tres veces. Aun así, se consiguió que 177 personas visitaran el enlace de la publicación. Esta muestra un conjunto de líneas horizontales; cada línea representa una de las verificaciones hechas por Ecuador Chequea y la emoción que provoca: miedo, ira, alegría, sorpresa y tristeza. El miedo y la ira son las emociones más comunes dentro de la muestra. 
Gráfico 2

Alcance de la publicación "Las emociones y la desinformación" Reacciones, en publicación y en contenido compartido

10

8
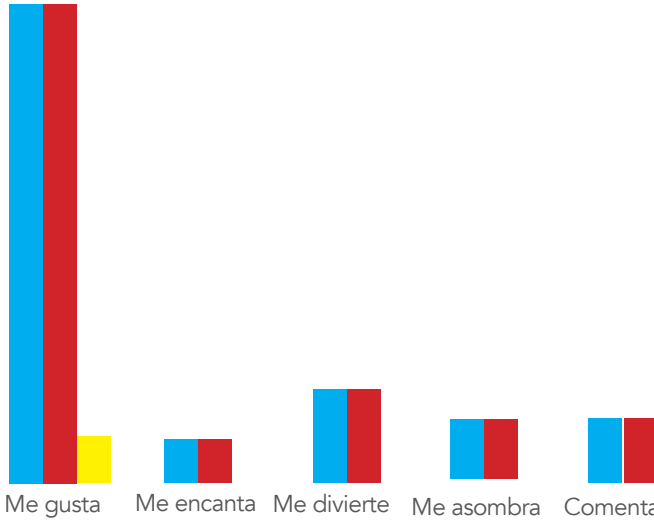

- Reacciones

- En publicación

- En contenido compartido

Fuente: Perfil de Facebook de ActualData

La tercera publicación se llamó "El ritmo de la desinformación". Aunque tuvo un alcance aproximado de 4541 personas, inferior a las anteriores, tuvo más interacción que la publicación de las emociones, con un total de 75 interacciones y once comentarios. Además, fue compartida siete veces, y se consiguió que siete personas visitaran el enlace.

Esta publicación muestra dos líneas de tiempo que comprenden el período de análisis, del 1 de enero al 30 de junio de 2020. La primera línea revela las fake news sobre el COVID-19 y la segunda, las relacionadas a otros temas. Se destaca el 23 de marzo como el día en el que más desinformaciones fueron verificadas.

Gráfico 3

Alcance de la publicación "El ritmo de la desinformación"

Reacciones, en publicación y en contenido compartido

60

40
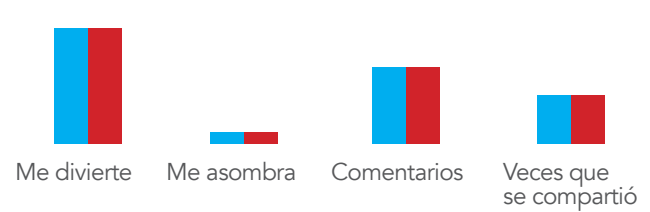

- Reacciones

- En publicación

- En contenido compartido

Fuente: Perfil de Facebook de ActualData 
El último arte de la campaña circuló en Facebook en enero de 2020 y hace referencia a los temas de la desinformación. Este aviso logró llegar a 10148 personas, aproximadamente. Aunque consiguió más alcance que el anterior, no superó al aviso del flujo, a pesar de que la inversión y el tiempo de exposición fueron los mismos en todos los casos. Además, obtuvo 127 reacciones, entre las cuales se destacan ampliamente 108 "me gusta".

Este arte muestra, mediante un diagrama de embalaje circular, qué temas fueron los más frecuentes en las verificaciones. Los relacionados a la enfermedad -como el número de casos o los tratamientos- y a la política fueron los temas comunes.

Gráfico 4

Alcance de la publicación "Los temas de la desinformación”

Reacciones, en publicación y en contenido compartido

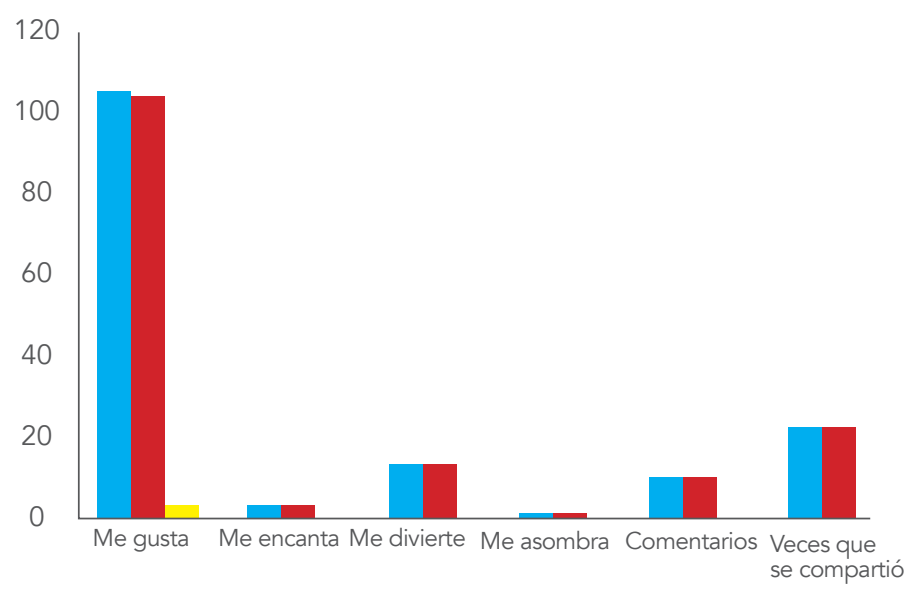

Fuente: Perfil de Facebook de ActualData

- Reacciones

- En publicación

En contenido compartido

Esta campaña contaba con otro arte adicional, "Una radiografía de la desinformación", pero el Centro de Anuncios de Facebook no lo aprobó debido a que mencionaba al mismo Facebook, aunque sin ninguna apreciación negativa. Solo se mencionaba que, debido a su alcance, es la red preferida para difundir noticias falsas, debido a la cantidad de información que contiene y porque los videos suelen ser manejados de manera diferente por el filtro de verificación. 


\section{Figura 6}

\section{Una radiografía de la desinformación}

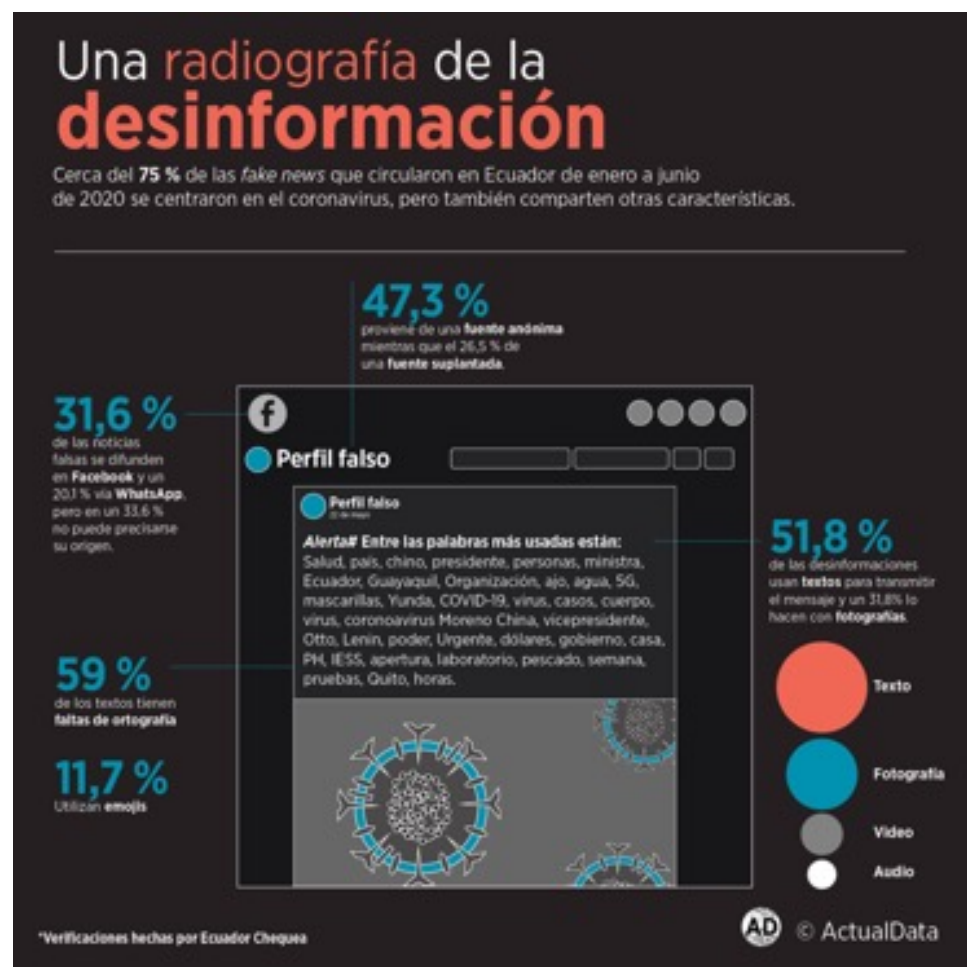

Fuente: Perfil de Facebook de ActualData

En el caso de Twitter, la publicación que obtuvo mejores métricas fue la de las emociones, en la etapa de expectativa, con 115 impresiones. En segundo lugar, el tema que más llamó la atención fue el referente a las emociones, pero en la etapa de lanzamiento, con 59 impresiones. Finalmente, en Instagram, el engagement fue muy bajo, incluso para las historias. Sin ninguna inversión, la cuenta consiguió 68 seguidores; el enriquecimiento de este perfil con imágenes relacionadas hizo posible que se sumaran más seguidores en el último mes de campaña

\section{Discusión y conclusiones}

Una respuesta articulada a la desinformación debe tener algunos puntos básicos: estar basada en valores y ser precisa, oportuna y atrevida. "Esto implica la necesidad de un enfoque más matizado y estratégico que la refutación. Esto se puede centrar en enmarcar la táctica de la desinformación, contextualizar y comunicar abiertamente los motivos o errores del agente/adversario, y no responder directamente al mensaje" (GB Government Communication Service 2019, 41). 
El ejercicio de verificación de la desinformación es necesario, más aún en circunstancias como las ocurridas durante este 2020, pero sin una comunicación efectiva ese esfuerzo puede verse diluido. Es necesario encontrar otras formas de transmitir el mensaje que vayan más allá de investigar su origen y posteriormente desmentirlo. El desarrollo de piezas gráficas que evidencien las similitudes o diferencias entre tipos tan diversos de información puede resultar una vía alternativa para contribuir a educar a la población, dado que la lucha contra este fenómeno tiene como pilar fundamental la educación.

En esta batalla, las herramientas y los enfoques son diversos, pero la Unesco sugiere diez tipos de respuestas agrupadas en cuatro categorías: respuestas de monitoreo y verificación; respuestas basadas en la gobernanza; respuestas curatoriales, técnicas y económicas; $y$, finalmente, respuestas dirigidas a los grupos que son blanco de la desinformación (Posetti y Bontcheva 2020b). Esta investigación se enmarca en este último grupo de respuestas, que busca el empoderamiento del público y de los periodistas o las personas que difunden información.

También se debe considerar el tono de la respuesta. Cambiar el relato de la simple verificación y presentarlo de una manera más interesante y novedosa puede contribuir al interés del público (GB Government Communication Service 2019). Los gráficos presentados para la campaña buscan mostrar otras formas de presentar la información, más allá de un pie o un gráfico de barras, y precisamente el que más interacciones obtuvo fue el menos común: el diagrama de Sankey que muestra el flujo de la información. Con esto se puede inferir que el público puede comprender este tipo de gráficos más complejos y menos frecuentes, y que se los puede usar como otras herramientas para la difusión de información.

La aparición de otras plataformas de verificación puede contribuir a la diversificación del mensaje, a encontrar otras maneras de comunicarlo y, sobre todo, a articular iniciativas de capacitación en las que resulta fundamental procesar la información y mostrarla al público de formas más interesantes, con el apoyo de otras disciplinas, replicando el ejemplo de este trabajo. A partir de septiembre de 2020 empezó a funcionar Ecuador Verifica, y ojalá otros medios o portales se sumen pronto, a pesar de ser un mercado tan pequeño.

Un punto fundamental para cualquier campaña de comunicación es conocer el grupo objetivo al cual va dirigida, pero la información al respecto en este fenómeno es muy general. Por lo tanto, otro tema importante que puede ser considerado para futuras investigaciones y que aportaría información para la lucha contra la desinformación es detectar los grupos etarios que son presas de los diferentes tipos de fake news, o los temas que más interesan a hombres y a mujeres, así como qué tipo de información falsa ya son capaces de reconocer.

Finalmente, se recomienda considerar que el estudio y la investigación de este fenómeno no pueden limitarse a la comunicación, y deben involucrar a otras áreas, como la psicología social, el derecho, la política y la filosofía (Montesi 2020). Ese enfoque multidisciplinario puede traer luces para comprender cómo nace y evoluciona la desinformación y, sobre todo, cómo combatirla. 


\section{Referencias}

Bayas, K. 2020. "Visualización del contexto de las fake news para entender la infodemia”. \#PerDebate 4: 90-109.

Código Vidrio. 2020. “Así propaga el correísmo el virus del miedo en redes”. Código Vidrio. 30 de marzo. https://bit.ly/3fp9tPo.

Costa, J. 1998. La esquemática: Visualizar la información. Madrid: Paidós.

Cusot, G. e I. Palacios. 2019. "Las fake news y las estrategias de verificación del discurso público: Caso Ecuador Chequea”. \#PerDebate 3: 88-107.

EC INEC. 2019. “Tecnologías de la Información y Comunicación: Encuesta Multipropósito-TIC”. Instituto Nacional de Estadística y Censos. https://bit.ly/3wDV1sG.

Ecuador Chequea. 2021. “Quiénes somos”. Ecuador Chequea. Accedido 28 de mayo. http://www.ecuadorchequea.com/quienes-somos.

Frascara, J. 1999. El poder de la imagen. Buenos Aires: Infinito.

GB Government Communication Service. 2019. "RESIST: Counter-Disinformation Toolkit”. Government Communication Service. https://bit.ly/3vxNaga.

Montesi, M. 2020. "Las fake news sobre el COVID-19: ¿qué aprendemos de ellas?” (inédito). https://bit.ly/3wBqdIU.

OMS. 2020. "Gestión de la infodemia sobre la COVID-19: Promover comportamientos saludables y mitigar los daños derivados de la información incorrecta y falsa". Organización Mundial de la Salud. 23 de septiembre. https://bit.ly/2ULeOJg.

Posetti, J., y K. Bontcheva. 2020a. "Desinfodemia: Descifrando la desinformación sobre el COVID-19”. Unesco. https://bit.ly/3yHgt1D.

—, y K. Bontcheva. 2020b. "Desinfodemia: Disección de las respuestas a la desinformación sobre el COVID-19”. Unesco. https://bit.ly/3bZq8H2.

Shaoqiang, W. 2017. Infografía. Barcelona: Promopress.

Ware, C. 2013. Information Visualization. Waltham, MA, US: Morgan Kaufmann.

Zarocostas J. 2020. “How to Fight an Infodemic”. Lancet 395 (10225): 676. https://doi.org/10.1016/ S0140-6736(20)30461-X 